\title{
Prevalence and factors associated with off-label antidepressant prescriptions for insomnia
}

This article was published in the following Dove Press journal:

Drug, Healthcare and Patient Safety

7 July 2011

Number of times this article has been viewed

\section{Leanne Lai'}

Mooi Heong Tan'

Yen Chi Lai ${ }^{2}$

'Department of Sociobehavioral and Administrative Pharmacy, College of Pharmacy, Nova Southeastern University, Fort Lauderdale, FL, USA; ${ }^{2}$ Department of Internal Medicine, Golen Hospital, Pintong City, Taiwan
Correspondence: $L$ Leanne Lai

Department of Sociobehavioral and Administrative Pharmacy, College of Pharmacy, Nova Southeastern University, 3200 S University Drive, Fort Lauderdale, FL 33328, USA

$\mathrm{Tel}+\mid 9542621320$

Fax + I 9542622278

Email leanne@nova.edu
Background: The primary objective of our study was to investigate the prevalence of off-label antidepressant drug use in insomnia. The secondary objective was to compare prescribing patterns between off-label antidepressants vs hypnotics approved by the US Food and Drug Administration for insomnia, with particular emphasis on socioeconomic characteristics of patients and physicians.

Methods: We undertook a secondary data analysis using the national longitudinal database from the 2006 National Ambulatory Medical Care Survey. Subjects were identified from outpatient visits in which at least one insomnia drug was prescribed. A series of weighted Chi-squared statistics was used to compare drug use for insomnia across various patient and physician characteristics. Multivariate logistic regression was conducted to identify factors associated with off-label antidepressant drug use.

Results: Among 901.95 million outpatient visits that took place in the US in 2006, an estimated 30.43 million visits included at least one drug prescription for insomnia. Off-label antidepressants were prescribed significantly more frequently (45.1\%) than nonbenzodiazepine z-hypnotics (43.2\%) and benzodiazepines (11.7\%). Insomnia prescribing patterns were significantly influenced by physician specialty and physician office settings. Pediatricians (odds ratio [OR]: 65.892; 95\% confidence interval [CI]: 5.536-810.564) and neurologists (OR: 4.784; 95\% CI: 2.044-11.201) were more likely to prescribe off-label antidepressants than psychiatrists. Self-paying patients were more likely to receive off-label antidepressants as treatment for insomnia than patients with private insurance (OR 2.594; 95\% CI: 1.128-5.967).

Conclusion: Our findings indicate significant socioeconomic disparities in the use of off-label antidepressants. Future studies might explore interventional and educational strategies to ensure well informed clinical decisions that can withstand pharmaceutical marketing strategies and diagnostic uncertainties regarding the treatment of insomnia.

Keywords: insomnia, off-label drug use, antidepressants, National Ambulatory Medical Care Survey

\section{Introduction}

Insomnia, defined as difficulty initiating and maintaining sleep, is currently the most prevalent sleep disorder. Approximately $20 \%$ of adults examined in a general medical setting experience severe and persistent insomnia. ${ }^{1}$ According to the National Sleep Foundation's 2008 "Sleep in America Poll”, as many as 65\% of adults report one or more sleep difficulties at least several times per week, with $44 \%$ experiencing sleep difficulties on a nightly basis. ${ }^{2}$ The costs of insomnia, both direct and indirect, range from US\$92.5 to US\$107.5 billion annually. ${ }^{3}$ However, the market for insomnia drugs 
is not saturated. There is a potential for increased drug sales and patient awareness of available treatments. Current prescription medications approved by the US Food and Drug Administration (FDA) for insomnia include five benzodiazepines (estazolam, flurazepam, quazepam, temazepam, and triazolam), three nonbenzodiazepine z-hypnotics (eszopiclone, zalepon, and zolpidem),${ }^{4}$ and one selective melatonin receptor agonist (ramelteon)..$^{5}$ Despite the availability of these drugs, studies consistently show a rise in off-label prescriptions for antidepressants, antipsychotics, and anticonvulsants in the treatment of insomnia. ${ }^{6,7}$ Antidepressants accounted for three of the most often prescribed hypnotics, which are trazodone, amitriptyline, and mirtazapine. ${ }^{8}$ In other reports, trazodone has contributed to approximately $20 \%$ of total insomnia drug sales in the market. ${ }^{9,10}$ However, there is growing concern that off-label use of antidepressants may also put patients at higher risk for medication errors, side effects, and unwanted drug reactions.

Off-label prescribing, also called "nonapproved" or "unapproved" use of a drug, is the practice of prescribing medication for purposes different from those indicated by the FDA. Off-label drug use contributes to approximately $21 \%$ of prescriptions written annually. ${ }^{11}$ The use of off-label drugs is not illegal and is regularly practiced across the country. The FDA does not regulate the practice of medicine, and this translates into freedom of off-label drug use by licensed practitioners. ${ }^{11,12}$ Numerous physicians believe it is a privilege accorded to the medical practitioner based on their professional experience under certain circumstances. It has been argued that off-label prescription provides a flexible and experimental platform for fostering the discovery of a new drug indication. ${ }^{11}$ Yet, specialists warn that off-label use may be more risky due to lack of safety and efficacy data. , $^{3,11}$

Amongst off-label drug uses, antidepressant use is one of the most common. ${ }^{11}$ Closely related to the issue of off-label antidepressant drug use for insomnia are sociodemographic characteristics of physicians and patients. Physicians may believe erroneously that off-label medications have demonstrated sustained efficacy and are safer. Physicians, as well as patients, may also choose antidepressants over hypnotics because of cost and formulary considerations. This decisionmaking process involves complicated socioeconomic issues and interactions between the patient and physician. These sociological influences were first considered by John Eisenberg, who identified a series of physician and patient characteristics likely to influence the allocation of a given prescription. ${ }^{13}$ Using Eisenberg's findings as a theoretical framework, several insomnia researchers have examined prescribing patterns across variables such as physician specialty, patient gender, and patient ethnicity. ${ }^{14-16}$

The literature has shown that off-label drug use is widespread but often not supported by strong evidence. ${ }^{11}$ To address this concern, the primary objective of our study was to investigate the prevalence of off-label antidepressant drug use in insomnia using a national representative database. The secondary objective was to compare prescribing patterns between off-label antidepressants vs FDA-approved hypnotics for insomnia, with particular emphasis on market-driven patient and physician socioeconomic characteristics.

\section{Methods \\ Data source}

Data were extracted from the National Ambulatory Medical Care Survey (NAMCS). The NAMCS is a national probability sample survey conducted annually by the Division of Health Care Statistics, National Center for Health Statistics, within the Centers for Disease Control and Prevention. The NAMCS sample data are collected from nonfederal officebased clinical practices. The basic sampling unit for the NAMCS is the physician-patient encounter or outpatient visit. For each selected visit, physicians complete an encounter form listing diagnoses, medication, and clinical services that they provided. All records contain patient demographic information, including age, gender, race, ethnicity, and source of payment. Details of the NAMCS sampling design are available to the public online. ${ }^{17}$ To enable extrapolation to national estimates, each visit record is assigned an inflation factor called the patient visit weight, which is then used to predict the total number of office visits made in the US. All estimates from the NAMCS are related to the number of patient visits and are subject to sampling variability. An estimate is considered reliable if it has a relative sampling error $\leq 30 \%$ of the estimate, as per NCHS standards. Our study used the 2006 NAMCS data for its timeliness and availability while this project was funded. All data management and analyses described were performed using SAS software (SAS Institute, Cary, NC).

\section{Data extraction and methods}

All patient visits to an ambulatory physician office, where at least one frequently used insomnia drug was prescribed, were extracted and categorized into two groups, ie, FDAapproved insomnia prescriptions, including benzodiazepine hypnotics (flurazepam, quazepam, triazolam, estazolam, temazepam), nonbenzodiazepine hypnotics (zolpidem, zaleplon, eszopiclone), and a selective melatonin receptor agonist 
(ramelteon), and frequently used off-label antidepressants for insomnia, including amitriptyline, nortriptyline, mirtazapine, doxepin, and trazodone. Up to eight medications can be recorded for each visit in the NAMCS database. Each drug code was assigned a unique "generic drug code" by Multum's Lexicon Plus system, which was used to classify drug entries in the NAMCS. The structure of the Multum database allows multiple-ingredient drugs to be assigned a single generic drug code according to their generic components and therapeutic classifications. Patients who were diagnosed with depression (ICD-9-CM codes 296.20, 296.30, 300.40, 309.00, 309.10, and 311.00) were excluded from the off-label antidepressant group to avoid overestimation of off-label antidepressant use. Using Eisenberg's sociological theory, we also identified several physician and patient characteristics as variables for further analysis, ie, patient age, gender, ethnicity, insurance type, physician's specialty, office setting, and office ownership. The study proposal was approved by the Institutional Review Board of Nova Southeastern University.

\section{Statistical analysis}

Each record on the NAMCS data file represents one patient visit. In order to obtain national estimates, the sample weight adjustments and standard error corrections were incorporated in all descriptive and inferential statistical analyses. We first performed a series of descriptive analyses to estimate the national weighted frequency of each drug. Second, we explored bivariate analyses to compare selected predictive variables associated with insomnia prescribing patterns between off-label antidepressants and FDA-approved hypnotics using weight-adjusted Chi-squared analyses. Third, a weighted multivariate logistic regression with SAS PROC SURVEYLOGISTICS application was conducted to predict the maximum likelihood of off-label antidepressant use associated with patient and physician socioeconomic characteristics. Both standard sample design variables (CSTRATM and CPSUM) were included in the SAS PROC SURVEYFREQ program to adjust for the complex sampling design employed by NAMCS. A two-tailed statistic with a $P$-value less than 0.05 was considered statistically significant.

\section{Results \\ Prevalence and bivariate analyses}

An estimated total of 901.95 million outpatient visits occurred in the US in 2006. There were 30.43 million visits (3.4\%) at which at least one frequently used insomnia drug was prescribed. FDA-approved benzodiazepines were prescribed at 3.53 million of these visits $(11.6 \%)$, whereas FDAapproved nonbenzodiazepine $z$-hypnotics were prescribed at 12.55 million visits (41.2\%). Non-FDA-approved insomnia medications were prescribed at 13.73 million visits (45.1\%). The weighted frequency of these drugs is presented in Table 1. The most frequently prescribed drug was zolpidem, which accounted for $32.8 \%$ of total prescriptions. This was followed by trazodone $(17.9 \%)$, amitriptyline $(14.5 \%)$, temazepam $(8.7 \%)$, eszopiclone $(7.5 \%)$, mirtazapine $(5.8 \%)$,

Table I Prevalence of insomnia drugs prescribed at US outpatient visits in 2006

\begin{tabular}{|c|c|c|c|}
\hline Insomnia drugs & Generic equivalent code & Weighted frequency & Percentage (\%) \\
\hline \multicolumn{4}{|c|}{ FDA-approved benzodiazepine hypnotics } \\
\hline Temazepam (Restoril ${ }^{\circledR}$ ) & $\mathrm{d} 00384$ & $2,644,074$ & $8.7 \%$ \\
\hline Estazolam (Prosom ${ }^{\circledR}$ ) & $\mathrm{d} 00915$ & 108,135 & $0.4 \%$ \\
\hline Triazolam $\left(\right.$ Halcion $\left.^{\circledR}\right)$ & d00397 & 535,258 & $1.8 \%$ \\
\hline Flurazepam (Dalmane ${ }^{\circledR}$ ) & d00238 & 249,686 & $0.8 \%$ \\
\hline Quazepam (Doral ${ }^{\circledR}$ ) & $\mathrm{d} 00917$ & 0 & $0 \%$ \\
\hline \multicolumn{4}{|c|}{ FDA-approved nonbenzodiazepine z-hypnotics } \\
\hline Zolpidem (Ambien ${ }^{\circledR}$ ) & d00910 & $9,996,496$ & $32.8 \%$ \\
\hline Zaleplon (Sonata ${ }^{\circledR}$ ) & d04452 & 265,363 & $0.9 \%$ \\
\hline Eszopiclone (Lunesta ${ }^{\circledR}$ ) & d0542I & $2,290,378$ & $7.5 \%$ \\
\hline \multicolumn{4}{|c|}{ Selective melatonin receptor agonist } \\
\hline Ramelteon (Rozerem ${ }^{\circledR}$ ) & d05778 & 614,907 & $2.0 \%$ \\
\hline \multicolumn{4}{|c|}{ Non FDA-approved antidepressants } \\
\hline Trazodone $\left(\right.$ Desyrel $\left.^{\circledR}\right)$ & d00395 & $5,435,674$ & $17.9 \%$ \\
\hline Amitriptyline $\left(\right.$ Elavil $\left.^{\circledR}\right)$ & $\mathrm{d} 00146$ & $4,413,467$ & $14.5 \%$ \\
\hline Mirtazapine (Remeron ${ }^{\circledR}$ ) & d04025 & $\mathrm{I}, 76 \mathrm{I}, 523$ & $5.8 \%$ \\
\hline Nortriptyline (Aventy ${ }^{\circledR}$ ) & $\mathrm{d} 00144$ & $1,424,346$ & $4.7 \%$ \\
\hline Doxepin $\left(\right.$ Sinequan ${ }^{\circledR}$ ) & d00217 & 695,369 & $2.3 \%$ \\
\hline Total & & $30,434,676$ & $100.0 \%$ \\
\hline
\end{tabular}

Note: Insomnia drugs selected according to the National Institutes of Health report ${ }^{4}$ and Rozerem ${ }^{\circledast}$ prescribing information. ${ }^{5}$ Abbreviation: FDA, Food and Drug Administration. 
nortriptyline $(4.7 \%)$, doxepin $(2.3 \%)$, ramelteon $(2.0 \%)$, triazolam $(1.8 \%)$, zaleplon $(0.9 \%)$, flurazepam $(0.8 \%)$, and estazolam $(0.4 \%)$. Figure 1 illustrates the prevalence of FDA-approved hypnotic and off-label antidepressant use in the treatment of insomnia.

Table 2 outlines the results from weight-adjusted Chisquared analyses comparing the off-label antidepressant group and the FDA-approved hypnotic group based on selected patient and physician characteristics. The off-label antidepressant group had a significantly lower mean age than the FDA-approved group (55.8 years vs 58.2 years, $P=0.0186$ ). In the off-label antidepressant group, female patients received more insomnia prescriptions than did men (68.2\% vs $31.8 \%$ ). Similar trends were observed in the FDA-approved hypnotic group (62.2\% vs $37.8 \%$ ). In both groups, white patients were more likely to receive insomnia drugs, followed by Hispanics, blacks, and other races. The majority of visits at which insomnia medications were prescribed were paid for by private insurance, Medicare, and Medicaid. This trend was consistent in both groups, but a significant difference was detected in the distribution based on payment mode.

Off-label antidepressant prescribing patterns were significantly influenced by physician specialty $(P<0.001)$ and physician office setting $(P<0.001)$. General practitioners/family physicians prescribed the most insomnia prescriptions (off-label antidepressant group 27.8\%, FDA-approved group $24.7 \%$ ), followed by internal medicine physicians (off-label antidepressant group 22.3\%, FDA-approved group $26.0 \%$ ) and psychiatric specialists (off-label antidepressant group 16.8\%, FDA-approved group 16.4\%, see Table 2 and Figure 2). The majority of insomnia prescriptions were issued by private solo/group practices (off-label antidepressant group $80.5 \%$, FDA-approved group 92.3\%). However, there was a statistically significant difference in the distribution of insomnia prescriptions between the off-label antidepressant group and FDA-approved hypnotic group. Clinics owned by physicians prescribed more insomnia prescriptions (offlabel antidepressant group 72.9\%, FDA-approved group $80.1 \%$ ) than other types of physician office ownership, such as a Health Maintenance Organization, community health center, or academic health center. However, no statistically significant difference in physician office ownership was found between the two groups.

\section{Multivariate analysis}

Results of multivariate logistic regression presented as odds ratios (OR) and 95\% Wald confidence intervals (CI) are shown in Table 3 . The adjusted OR represents the increased

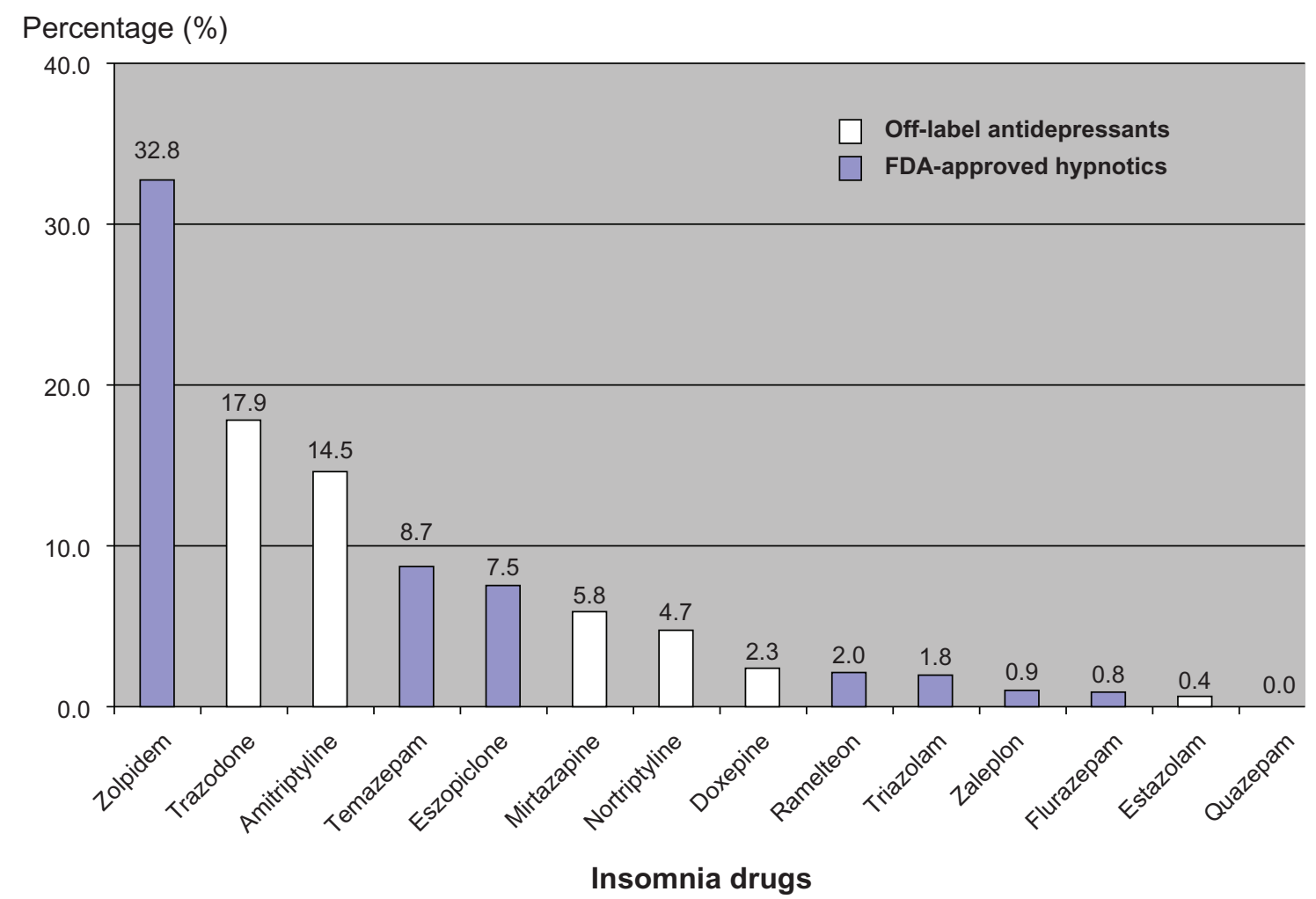

Figure I Prevalence of FDA-approved hypnotics and off-label antidepressants use in the treatment of insomnia. Abbreviation: FDA, Food and Drug Administration. 
Table 2 Socioeconomic characteristics of off-label antidepressant group and FDA-approved hypnotic group

\begin{tabular}{|c|c|c|c|}
\hline \multirow[t]{2}{*}{ Variable } & \multicolumn{2}{|l|}{ Weighted frequency (\%) } & \multirow[t]{2}{*}{$P$-value* } \\
\hline & Off-label antidepressant group & FDA-approved hypnotic group & \\
\hline \multicolumn{4}{|l|}{ Patient age } \\
\hline Mean (years) & 55.775 & 58.155 & $0.0186 *$ \\
\hline \multicolumn{4}{|l|}{ Patient gender } \\
\hline Female & $9,274,657(68.2)$ & $10,423,770(62.2)$ & 0.2145 \\
\hline Male & $4,325,960(31.8)$ & $6,325,183(37.8)$ & \\
\hline \multicolumn{4}{|l|}{ Patient race } \\
\hline White, non-hispanic & $10,286,943(75.6)$ & $|2,557,4| 0(75.0)$ & 0.4536 \\
\hline Black, non-hispanic & $\mathrm{I}, 28 \mathrm{I}, 507(9.4)$ & $\mathrm{I}, 435,060(8.6)$ & \\
\hline Hispanic & I,324,7। 5 (9.7) & $2,058,405(12.3)$ & \\
\hline Asian & $4 I I, 237(3.0)$ & $573,677(3.4)$ & \\
\hline Native Hawaiian, other Pacific Islander & $21,672(0.2)$ & $35,529(0.2)$ & \\
\hline American Indian/Alaska Native & $23|, 5| 8(1.7)$ & $88,872(0.5)$ & \\
\hline Multiple races & $43,025(0.3)$ & $0(0.0)$ & \\
\hline \multicolumn{4}{|l|}{ Physician specialty } \\
\hline General/family practice & $3,779,358(27.8)$ & $4,139,900(24.7)$ & $<0.00 I^{*}$ \\
\hline Internal medicine & $3,028,144(22.3)$ & $4,347,494(26.0)$ & \\
\hline Pediatrics & $214,920(1.6)$ & $4,690(0.0)$ & \\
\hline General surgery & 257,555 (1.9) & I8I,795 (I.I) & \\
\hline Obstetrics and gynecology & $302, \mid 43(2.2)$ & $225,152(1.3)$ & \\
\hline Orthopedic surgery & $316,399(2.3)$ & $678,631(4.1)$ & \\
\hline Cardiovascular diseases & $456,555(3.4)$ & $602,225(3.6)$ & \\
\hline Dermatology & $84,648(0.6)$ & $103,652(0.6)$ & \\
\hline Urology & $152,834(1.1)$ & $149,935(0.9)$ & \\
\hline Psychiatry & $2,287,602(16.8)$ & $2,746,794(16.4)$ & \\
\hline Neurology & $881,278(6.5)$ & $386,081(2.3)$ & \\
\hline Ophthalmology & $96,370(0.7)$ & $0(0.0)$ & \\
\hline Otolaryngology & $99,222(0.7)$ & $104,060(0.6)$ & \\
\hline Other specialties & $1,452,388(10.7)$ & $2,556,955(15.3)$ & \\
\hline Oncology & 191,201 (1.4) & $521,589(3.1)$ & \\
\hline \multicolumn{4}{|l|}{ Physician office setting } \\
\hline Private solo/group practice & I0,94I,224 (80.5) & $15,463,752(92.3)$ & $<0.00 I^{*}$ \\
\hline Free standing clinic/urgent center & $\mathrm{I}, 44 \mathrm{I}, 709(10.6)$ & $605,762(3.6)$ & \\
\hline Community health center & $391,458(2.9)$ & $233,423(1.4)$ & \\
\hline Mental health center & $272,676(2.0)$ & $152,946(0.9)$ & \\
\hline Nonfederal government clinic & $28,734(0.2)$ & $0(0.0)$ & \\
\hline HMO or other prepaid practice & $499,100(3.7)$ & $223,104(1.3)$ & \\
\hline Faculty practice plan & $25,716(0.2)$ & $69,966(0.4)$ & \\
\hline \multicolumn{4}{|l|}{ Physician office ownership } \\
\hline Physician or physician group & $9,920,33$ I (72.9) & $|3,4| \mid, 483(80.1)$ & 0.5634 \\
\hline HMO* & $573,486(4.2)$ & $348,105(2.1)$ & \\
\hline Community health center & $370,576(2.7)$ & $228,249(1.4)$ & \\
\hline Medical/academic health center & $539,177(4.0)$ & $378,685(2.3)$ & \\
\hline Other hospital & $843,240(6.2)$ & $819,082(4.9)$ & \\
\hline Other health care corporation & I,07I,752 (7.9) & $1,270,305(7.6)$ & \\
\hline Other & $282,055(2.1)$ & $211,025(1.3)$ & \\
\hline Blank & $0(0.0)$ & $82,019(0.5)$ & \\
\hline \multicolumn{4}{|l|}{ Type of payment } \\
\hline Blank & $396,496(2.9)$ & $216,360(1.3)$ & $0.0342 *$ \\
\hline Private insurance & $5,288,962(38.9)$ & $7,799,779(46.6)$ & \\
\hline Medicare & $4,400,684(32.4)$ & $5,546,188(33.1)$ & \\
\hline Medicaid & $2,096,614(15.4)$ & I,85I,407 (II.I) & \\
\hline Worker's compensation & $18,240(0.1)$ & $|97| 4 \mid,(1.2)$ & \\
\hline Selfpay & $740,144(5.4)$ & $395,585(2.4)$ & \\
\hline No charge & $|7|, 98 \mid(1.3)$ & $28,168(0.2)$ & \\
\hline Other & $209,478(1.5)$ & $229,839(1.4)$ & \\
\hline Unknown & $278,018(2.0)$ & $484,486(2.9)$ & \\
\hline
\end{tabular}

Note: *Indicates that weight-adjusted Chi-squared statistic is significant.

Abbreviations: HMO, Health Maintenance Organization; FDA, Food and Drug Administration. 


\section{Percentage (\%)}



Physician specialty

Figure 2 Distribution of off-label antidepressants and FDA-approved hypnotic prescriptions based on physician specialty. Abbreviation: FDA, Food and Drug Administration.

likelihood of prescribing off-label antidepressants compared with FDA-approved hypnotics based on each socioeconomic characteristic, using a reference group in each category.

There was no significantly increased likelihood of prescribing off-label antidepressants in relation to patient age, gender, and ethnicity. However, self-paying patients were more likely to receive off-label antidepressants for insomnia than patients with private insurance (OR: 2.594; 95\% CI: 1.128-5.967). In contrast, certain physician characteristics significantly increased the likelihood of prescribing off-label antidepressants for treatment of insomnia. Physicians from most specialties did not show an increased likelihood of prescribing off-label antidepressants, except for pediatricians and neurologists. Pediatricians (OR: 65.892; 95\% CI: 5.536-810.564) and neurologists (OR: 4.784; 95\% CI: 2.044-11.201) were more likely than psychiatrists to prescribe off-label antidepressants. Physicians from freestanding clinics or urgent centers were also more likely to prescribe off-label antidepressants than those from private solo/group practices (OR: 3.26; 95\% CI: 1.2-8.9).

\section{Discussion}

Of 901.95 million outpatient visits in the US in 2006, at least one insomnia drug was prescribed at 30.43 million visits, representing approximately $3.4 \%$ of visits, as opposed to the estimated $20 \%$ of adults reported to experience severe and persistent insomnia. ${ }^{1}$ This discrepancy could be due to selective "underprescribing", a phenomenon that has been detected in other chronic diseases. ${ }^{18,19}$ However, widespread use of over-the-counter antihistamines might be another reason for this occurrence. According to the National Institutes of Health, alcohol and over-the-counter drugs remain some of the most popular selfcare treatments for insomnia., ${ }^{4,20}$

Off-label antidepressants were prescribed in $45.1 \%$ of the prescriptions examined. This is nearly four times the amount of FDA-approved benzodiazepine prescriptions issued. The high prevalent use of off-label antidepressants for insomnia has been reported in other studies. ${ }^{21,22}$ Wiegand postulated that physicians favor antidepressants over FDA-approved benzodiazepines due to uninformed perceptions of the safety and nonaddictive advantages of antidepressants over benzodiazepine receptor agonists..$^{23}$ It is equally likely that comorbidity with depression and anxiety disorders result in increased use of off-label antidepressants for insomnia treatment. ${ }^{24}$ An estimated $40 \%$ of all patients with insomnia have a coexisting psychiatric condition, ${ }^{25}$ and differences between insomnia and depressive symptoms can be ambiguous. ${ }^{26}$ Although the diagnosis of depression was used as an exclusion criterion in our study, the influence of subclinical 
Table 3 Likelihood of prescribing off-label antidepressants in the treatment of insomnia

\begin{tabular}{|c|c|c|}
\hline Variable & Adjusted odds ratio & 95\% Wald confidence interval \\
\hline \multicolumn{3}{|l|}{ Patient age (years) } \\
\hline$<15$ & 0.870 & $0.153-4.932$ \\
\hline $15-24$ & 1.853 & $0.730-4.704$ \\
\hline $25-44$ & 0.827 & $0.425-1.609$ \\
\hline $45-64$ & 1.035 & $0.567-1.888$ \\
\hline $65-74$ & 1.019 & $0.532-1.95 \mid$ \\
\hline Above 75 years (reference) & - & - \\
\hline \multicolumn{3}{|l|}{ Patient gender } \\
\hline Female & 1.219 & $0.850-1.750$ \\
\hline Male (reference) & - & - \\
\hline \multicolumn{3}{|l|}{ Patient race } \\
\hline White, non-hispanic (reference) & - & - \\
\hline Black, non-hispanic & 0.816 & $0.35 \mathrm{I}-1.896$ \\
\hline Hispanic & 0.706 & $0.372-1.338$ \\
\hline Asian & 0.634 & $0.246-1.629$ \\
\hline Native Hawaiian, other Pacific Islander & 0.260 & $0.015-4.385$ \\
\hline American Indian/Alaska Native & 2.176 & $0.232-20.424$ \\
\hline \multicolumn{3}{|l|}{ Physician specialty } \\
\hline General/family practice & 1.811 & $0.867-3.783$ \\
\hline Internal medicine & 1.122 & $0.477-2.638$ \\
\hline Pediatrics & 65.892 & $5.536-810.564 *$ \\
\hline General surgery & 3.136 & $0.817-12.030$ \\
\hline Obstetrics and gynecology & 2.656 & $0.770-9.164$ \\
\hline Orthopedic surgery & 1.406 & $0.398-4.968$ \\
\hline Cardiovascular diseases & 1.428 & $0.572-3.564$ \\
\hline Dermatology & 1.328 & $0.243-7.258$ \\
\hline Urology & 1.552 & $0.458-5.261$ \\
\hline Psychiatry (reference) & - & - \\
\hline Neurology & 4.784 & $2.044-11.201 *$ \\
\hline Otolaryngology & 2.015 & $0.611-6.649$ \\
\hline Other specialties & 1.088 & $0.460-2.578$ \\
\hline Oncology & 0.564 & $0.232-1.368$ \\
\hline \multicolumn{3}{|l|}{ Physician office setting } \\
\hline Private solo/group practice (reference) & - & - \\
\hline Free standing clinic/urgent center & 3.255 & I.186-8.938* \\
\hline Community health center & 2.970 & $0.543-16.254$ \\
\hline Mental health center & 2.880 & $0.987-8.402$ \\
\hline HMO* or other prepaid practice & 4.000 & $0.696-22.994$ \\
\hline Faculty practice plan & 0.450 & $0.029-7.013$ \\
\hline \multicolumn{3}{|l|}{ Physician office ownership } \\
\hline Physician or physician group (reference) & - & - \\
\hline HMO & 2.217 & $0.50 I-9.8 I I$ \\
\hline Community health center & 1.222 & $0.183-8.137$ \\
\hline Medical/academic health center & 2.372 & $0.756-7.445$ \\
\hline Other hospital & 2.435 & $0.633-9.359$ \\
\hline Other health care corporation & 2.298 & $0.948-5.570$ \\
\hline Other & 1.603 & $0.422-6.090$ \\
\hline \multicolumn{3}{|l|}{ Type of payment } \\
\hline Private insurance (reference) & - & - \\
\hline Medicare & 1.433 & $0.858-2.394$ \\
\hline Medicaid & 1.617 & $0.888-2.947$ \\
\hline Worker's compensation & 0.230 & $0.024-2.175$ \\
\hline Selfpay & 2.594 & I.128-5.967* \\
\hline No charge & 6.630 & $0.724-60.713$ \\
\hline Other & 1.728 & $0.292-10.229$ \\
\hline Unknown & 0.745 & $0.234-2.374$ \\
\hline
\end{tabular}

Note: *Indicates adjusted odds ratio with $95 \%$ confidence interval is significant.

Abbreviation: HMO, Health Maintenance Organization. 
depression in the prescribing of off-label antidepressants cannot be ruled out. Even though prescribing antidepressants in the context of concurrent depression and insomnia is desirable, its use in the treatment of insomnia alone is unclear and arguably weak. ${ }^{6,23,27}$ Several randomized controlled trials have investigated the efficacy of antidepressants for insomnia, ${ }^{28-31}$ but only a few studies have directly compared its efficacy with that of the benzodiazepine receptor agonists. ${ }^{32,33}$ No comparison with z-hypnotics has been conducted to date.

The high prevalence of off-label antidepressant use for treatment of insomnia may also be attributed to its lower cost, given that generic preparations are widely available. However, drug pricing does not fully explain our findings. A recent report cites the economically accessible trazodone as the most frequently prescribed insomnia medication. ${ }^{34}$ Our results show that zolpidem accounted for more prescriptions than did trazodone, which is consistent with a report by Roy and Smith. ${ }^{35}$ This finding may be explained by the distributor's aggressive marketing efforts, such as direct-to-consumer advertising (DTCA). DTCA spending for zolpidem $\left(\right.$ Ambien $\left.^{\circledR}\right)$ was US\$11.1 million in 2000 and zolpidem was ranked as the 48th highest DTCA expenditure drug. ${ }^{36}$ A subsequent study by Donohue et al showed that this figure increased to US\$88 million in 2005, when zolpidem ranked the 14th highest DTCA expenditure drug. ${ }^{37}$ This amount has increased eight times within 5 years and DTCA is likely to have helped to secure its widespread usage, despite its reported side effects such as night-time eating, sleepwalking, daytime dizziness, and drowsiness. ${ }^{38,39}$ The impact of DTCA is explained by a survey in which $25 \%-33 \%$ of consumers talked to their physicians about the advertised drug they had seen, and $12 \%-25 \%$ of them asked to be prescribed the drug. ${ }^{40}$

It is surprising that there is high consistency in terms of the percentage of patients prescribed off-label antidepressants and FDA-approved hypnotics. This suggests that, despite the availability of FDA-approved hypnotics and their proven efficacy, approximately half of all physicians are still prescribing off-label antidepressants for insomnia. Using logistic regression analysis, we identified pediatricians and neurologists as being more likely to prescribe off-label antidepressants than psychiatrists. The practice of prescribing hypnotics for pediatric insomnia is common among special needs children, particularly those with a depressive disorder. Thus, off-label antidepressants may be a complementary choice for the treatment of insomnia in this population. In addition, concerns over the misuse of benzodiazepines and z-hypnotics in the pediatric population may increase the likelihood of pediatricians prescribing off-label antidepressants. Increased use of off-label antidepressants may be attributed to concurrent neurological symptoms reported by patients, such as neuropathic pain, that lead to difficulty sleeping.

Our study also found that physicians practicing at freestanding clinics or urgent centers were 3.26 times more likely to prescribe an off-label antidepressant for treatment of insomnia than those practicing at private solo/group practices. There are many freestanding clinics (ie, not associated with a medical institution) that offer off-label treatment for various health conditions. These treatments are usually provided based upon cash payment, which is consistent with our study finding that self-paying patients were 2.59 times more likely to obtain an off-label antidepressant than those with private insurance.

Nevertheless, our study has several limitations. First, we showed that neurologists prescribed 4.8 times more off-label antidepressants than psychiatrists for treatment of insomnia. This finding may be confounded by other off-label antidepressant use, eg, for neuropathic pain, migraine prophylaxis, tension headache, fibromyalgia, and other indications. The presence of these concurrent complaints may increase the likelihood of physicians prescribing off-label antidepressants for treatment of insomnia. ${ }^{41}$ On the other hand, the addition of these diagnoses to the exclusion criteria for the off-label antidepressant group may underestimate the likelihood of prescribing off-label antidepressants for insomnia because of the coexistence of these symptoms with insomnia. However, there is also the possibility of overestimating the study effect due to use of ICD-9 codes for the exclusion of patients with depression from the off-label antidepressant group. The tendency to underdiagnose depression may be attributed to ICD coding and, therefore, many patients without an ICD-9 code for depression were prescribed an antidepressant and included in the analysis.

Second, we used drug prescriptions for insomnia without an ICD-9 code because inclusion criteria may erroneously include patients without insomnia, as discussed earlier. Insomnia is frequently perceived as a symptom rather than a disorder, and ambiguity between insomnia and other psychiatric disorders render the use of the ICD-9 code inadequate. It is not uncommon for sedative antidepressants to be used in patients with depression and/or anxiety because of concurrent sleep difficulty. Additionally, our study did not take into account important reimbursement policies and institutional formularies that place restrictions on physicians' prescribing behaviors. Due to the limitations of the NAMCS database, our results did not provide qualitative information on the physician-patient relationship which could be used 
to formulate a physician education program in the future. We also did not take into consideration the effect of marital status in our analysis of demographic-based difference in prescribing patterns, as suggested by Brownlee et al. ${ }^{42}$

\section{Conclusion}

Our study confirms and expands on the findings of previous research to suggest profound sociodemographic and economic influences on insomnia prescribing patterns. Changing long-established physician prescribing patterns can be difficult, particularly if physicians have specific reasons for prescribing medications to specific populations. Future studies could explore intervention and educational strategies to ensure well informed clinical decisions that can withstand pharmaceutical marketing strategies and diagnostic uncertainties regarding the treatment of insomnia.

\section{Acknowledgments}

The study was funded by Nova Southeastern University President's Faculty Research and Development Grant. Special thanks to data support from the Ambulatory and Hospital Care Statistics Branch, National Center for Health Statistics.

\section{Disclosure}

The authors report no conflicts of interest in this work.

\section{References}

1. Smith MT, Neubauer DN. Cognitive behavior therapy for chronic insomnia. Clin Cornerstone. 2003;5(3):28-40.

2. National Sleep Foundation. 2008, Sleep in America. Available at: http:// www.sleepfoundation.org/sites/default/files/2008\%20POLL\%20SOF. pdf. Accessed November 20, 2010.

3. Stoller MK. Economic effects of insomnia. Clin Ther. 1994;16(5): 873-897.

4. National Institute of Health. State-of-the-science conference statement on manifestations and management of chronic insomnia in adults. $N I H$ Consens State Sci Statements. 2005;22(2):1-30.

5. Rozerem ${ }^{\circledR}$ [Prescribing information]. Deerfield, IL: Takeda Pharmaceuticals America, Inc; 2010.

6. Walsh JK, Schweitzer PK. Ten-year trends in the pharmacological treatment of insomnia. Sleep. 1999;22(3):371-375.

7. Balkrishnan R, Joish VN, Bhosle MJ, et al. Prior authorization of newer insomnia medications in managed care: Is it cost saving? J Clin Sleep Med. 2007;3(4):393-398.

8. IMS monthly Rx audit. March 2003-February 2006.

9. Neubauer DN. The evolution and development of insomnia pharmacotherapies. J Clin Sleep Med. 2007;3(5 Suppl):S11-S16.

10. Randall T. Kennedy hearings say no more free lunch - or much else from drug firms. JAMA. 1991;265(4):440-442.

11. Stafford RS. Regulating off-label drug use - rethinking the role of the FDA. N Engl J Med. 2008;358(14):1427-1479.

12. Chen H, Desphane A, Jiang R, Martin B. An epidemiological investigation of off-label anticonvulsant drug use in the Georgia Medicaid population. Pharmacoepidemiol Drug Saf. 2005;14(9):629-638.
13. Eisenberg JM. Sociologic influence on decision-making by clinicians. Ann Intern Med. 1979;90(6):957-964.

14. Stojanovski SD, Rasu RS, Balkrishnan R, et al. Trends in medication prescribing for pediatric sleep difficulties in US outpatient settings. Sleep. 2007;30(8):1013-1017.

15. Morlock RJ, Tan M, Mitchell DY. Patient characteristics and patterns of drug use for sleep complaints in the United States: Analysis of National Ambulatory Medical Survey data, 1997-2002. Clin Ther. 2006;28 (7): 1044-1053.

16. Skaer TL, Robison LM, Sclar DA, et al. Psychiatric comorbidity and pharmacological treatment patterns among patients presenting with insomnia: An assessment of office-based encounters in the USA in 1995 and 1996. Clin Drug Investig. 1999;18(2):161-167.

17. Centers for Disease Control and Prevention. Available at: http://www. cdc.gov/nchs/ahcd.htm. Accessed December 21, 2010.

18. Bennett KE, Williams D, Feely J. Under-prescribing of cardiovascular therapies for diabetes in primary care. Eur J Clin Pharmacol. 2003;58(12):835-841.

19. Nolan D, White R. Symptomatic asthma: Attendance and prescribing in general practice. Respir Med. 2002;96(2):102-109.

20. National Sleep Foundation. 2010 Sleep in America Poll: Summary of findings. Available at: http://www.sleepfoundation.org/sites/default/ files/nsaw/NSF\%20Sleep $\% 20$ in $\% 20 \% 20$ America $\% 20$ Poll $\% 20-\% 20$ Summary\%20of\%20Findings\%20.pdf. Accessed December 21, 2010.

21. Simon GE, VonKorff M. Prevalence, burden, and treatment of insomnia in primary care. Am J Psychiatry. 1997;154(10):1417-1423.

22. Morlock RJ, Tan M, Mitchell DY. Patient characteristics and patterns of drug use for sleep complaints in the United States: Analysis of National Ambulatory Medical Survey data, 1997-2002. Clin Ther. 2006;28(7): 1044-1053.

23. Wiegand MH. Antidepressants for the treatment of insomnia: A suitable approach? Drugs. 2008;68 (17):2411-2417.

24. Erman MK. Therapeutic options in the treatment of insomnia. J Clin Psychiatry. 2005;66(Suppl 9):18-23.

25. Ford DE, Kamerow DB. Epidemiologic study of sleep disturbances and psychiatric disorders. An opportunity for prevention. JAMA. 1989;262(11):1479-1484.

26. Ohayon MM. Prevalence of DSM-IV diagnostic criteria of insomnia: Distinguishing insomnia related to mental disorders from sleep disorders. J Psychiatr Res. 1997;31(3):333-346.

27. Taggart LAP, McCammon SL, Allred LJ, et al. Effect of patient and physician gender on prescriptions for psychotropic drugs. $J$ Womens Health. 1993;2(4):353-357.

28. Wichniak A, Wierzbicka A, Sobańska A, et al. The effectiveness of treatment with trazodone in patients with primary insomnia without and with prior history of hypnotics use. Pol Merkur Lekarski. 2007;23(133): 41-46. Polish.

29. Roth T, Rogowski R, Hull S, et al. Efficacy and safety of doxepin $1 \mathrm{mg}$, $3 \mathrm{mg}$, and $6 \mathrm{mg}$ in adults with primary insomnia. Sleep. 2007;30(11): $1555-1561$.

30. Hajak G, Rodenbeck A, Voderholzer U, et al. Doxepin in the treatment of primary insomnia: A placebo-controlled, double-blind, polysomnographic study. J Clin Psychiatry. 2001;62(6):453-463.

31. Hohagen F, Montero RF, Weiss E, et al. Treatment of primary insomnia with trimipramine: An alternative to benzodiazepine hypnotics? Eur Arch Psychiatry Clin Neurosci. 1994;244(2):65-72.

32. Walsh JK, Erman M, Erwin CW, et al. Subjective hypnotic efficacy of trazodone and zolpidem in DSM III-R primary insomnia. Hum Psychopharmacol Clin Exp. 1998;13(5):191-198.

33. Riemann D, Voderholzer U, Cohrs S, et al. Trimipramine in primary insomnia: Results of a polysomnographic double-blind controlled study. Pharmacopsychiatry. 2002;35(5):165-174.

34. Walsh JK. Drugs used to treat insomnia in 2002: Regulatory-based rather than evidence-based medicine. Sleep. 2004;27(8):1441-1442.

35. Roy AN, Smith M. Prevalence and cost of insomnia in a state Medicaid fee-for-service population based on diagnostic codes and prescription utilization. Sleep Med. 2010;11(5):462-469. 
36. National Institute for Health Care Management Foundation. Prescription Drugs and Mass Media Advertising, November 2001. Available at: http://nihcm.org/pdf/DTCbrief2001.pdf. Accessed December 21, 2010.

37. Donohue JM, Cevasco M, Rosenthal MB. A decade of direct-toconsumer advertising of prescription drugs. N Engl J Med. 2007;357(7): 673-681.

38. Dolder CR, Nelson MH. Hypnosedative-induced complex behaviours: Incidence, mechanisms and management. CNS Drugs. 2008;22(12): 1021-1036.

39. Siriwardena AN, Qureshi MZ, Dyas JV, et al. Magic bullets for insomnia? Patients' use and experiences of newer ( $Z$ drugs) versus older (benzodiazepine) hypnotics for sleep problems in primary care. Br J Gen Pract. 2008;58(551):417-422.
40. National Institute for Health Care Management Foundation. DTC Advertising: Is it helping or hurting? September, 2002. Available at: http://nihcm.org/pdf/DTCAdvertisingIsItHelpingorHurting.pdf. Accessed December 21, 2010.

41. Micromedex ${ }^{\circledR} 2.0$ Healthcare Series. Available at: http://wwwthomsonhc-com.ezproxylocal.library.nova.edu/hcs/librarian. Accessed December 27, 2010.

42. Brownlee K, Devins GM, Flanigan M, et al. Are there gender differences in the prescribing of hypnotic medications for insomnia? Hum Psychopharmacol. 2003;18(1):69-73.

\section{Publish your work in this journal}

Drug, Healthcare and Patient Safety is an international, peer-reviewed open-access journal exploring patient safety issues in the healthcare continuum from diagnostic and screening interventions through to treatment, drug therapy and surgery. The journal is characterized by the rapid reporting of reviews, original research, clinical, epidemiological and post-marketing surveillance studies, risk management, health literacy and educational programs across all areas of healthcare delivery. The manuscript management system is completely online and includes a very quick and fair peer-review system. Visit http://www.dovepress.com/ testimonials.php to read real quotes from published authors. 